\title{
Glottic and Tracheal Stenosis in Spinal Cord Injured Patients *
}

\author{
S. Hsu, M.D., J. N. Dreisbach, M.D., S. W. Charlifue, M.A., \\ G. M. English, M.D., F.A.C.S. \\ Rocky Mountain Regional Spinal Cord Injury System, Craig Hospital and Swedish \\ Medical Center, 3425 South Clarkson Street, Englewood, Colorado 80110, U.S.A.
}

\section{Summary}

Between 1965 and 1985, 47 cases of glottic and/or tracheal stenosis were diagnosed at the Rocky Mountain Regional Spinal Cord Injury System. A retrospective review of medical records identified associated injuries, pulmonary and other medical complications in this patient population. Radiographic and endoscopic reviews utilised a grading system to classify the severity of stenosis. The clinical symptoms of stenosis were multiple, including dysphonia, aspiration, dysphagia, odynophagia, dyspnea and excessive secretions. The wide spectrum of treatment modalities included endoscopy with excision and/or dilation, general medical management, steroids, radiation therapy, intubation, stent insertion and surgical repair of the stenotic area. Outcome status was reviewed and suggestions provided for the early diagnosis and treatment of this potentially life-threatening condition.

Key words: Intubation; Laryngostenosis; Spinal cord injuries; Tracheal stenosis; Tracheotomy.

\section{Introduction}

A variety of circumstances, such as internal or external trauma, endotracheal intubation or tracheotomy, benign or malignant neoplasms, irradiation and congenital anomalies, can cause glottic or tracheal stenosis. In 1932 Clausen reported the first case of post-intubation subglottic granuloma and these problems have been described widely in the literature since that time. There has been little information available, however, regarding the problems of glottic or tracheal stenosis in a spinal cord injured (SCI) population (Grillo, 1979; Baker, et al., 1984).

Intubation may be necessary for the treatment of respiratory failure. In the SCI individual, intubation may be indicated for airway protection or maintenance, assisted ventilation and pulmonary hygiene. The complications of endo-

* This paper was presented at the Twelf th Annual Scientific Meeting of the American Spinal Injury Association in San Francisco, California in March, 1986. 
tracheal intubation and tracheotomy are the same in the general population as in $\mathrm{SCI}$; however, stenosis is more poorly tolerated in the quadriplegic or paraplegic who has compromised respiratory function. This study describes the complications and treatment methods utilised in SCI individuals with glottic or tracheal stenosis.

\section{Patients and methods}

Between 1 January 1965 and 31 December 1985, forty-seven SCI patients were diagnosed to have glottic or tracheal stenosis. The diagnoses were made on the basis of symptomatology, physical findings, endoscopic examination, polytomography and CT scan. A retrospective analysis of the patients' medical records and $x$-ray films was performed. The following classification system was used to grade the severity of stenosis: Grade I (mild)-less than $20 \%$ stenosis; Grade II (moderate)-20\% to $<50 \%$ stenosis; Grade III (severe)-50\% to $<80^{\circ} \%$ stenosis; Grade IV (inability to pass endoscope or complete airway obstruction) $\longrightarrow>80 \%$ stenosis.

\section{Results}

During the 21-year period of the study, there were 3877 first admission SCI patients, of whom $47(1.2 \%$ incidence $)$ were diagnosed to have glottic or tracheal stenosis. This may not be the true incidence of the disease process, as less severe cases may not have been diagnosed in the earlier years: the incidence between 1979 and 1985 was $2.0 \%$. The patients included in this study consisted of 38 males and nine females with a mean age of 30.6 years. The ages ranged from 15 to 62 .

The causes of injury are illustrated in Table I. Motor vehicle accidents

Table I Etiology

\begin{tabular}{lcc}
\hline & No. & $\%$ \\
\hline Motor vehicle accident & 30 & $(64 \%)$ \\
Sports & 7 & $(15 \%)$ \\
Struck by object & 3 & $(6 \%)$ \\
Gunshot wound & 3 & $(6 \%)$ \\
Diving & 2 & $(4 \%)$ \\
Fall & 1 & $(2 \%)$ \\
Other & 1 & $(2 \%)$ \\
\hline
\end{tabular}

Table II Last Preserved Neurologic Level

\begin{tabular}{ccc}
\hline & No. & $\%$ \\
\hline C2 & 6 & $(13 \%)$ \\
C3 & 9 & $(19 \%)$ \\
C4 & 9 & $(19 \%)$ \\
C5 & 8 & $(17 \%)$ \\
C6 & 6 & $(13 \%)$ \\
C7 & 4 & $(9 \%)$ \\
T4 & 2 & $(4 \%)$ \\
T5 & 1 & $(2 \%)$ \\
T6 & 1 & $(2 \%)$ \\
T7 & 1 & $(2 \%)$ \\
\hline
\end{tabular}


accounted for $64 \%$ of the injuries, followed by sports-related accidents at $15 \%$. The last fully preserved neurological levels are indicated in Table II. Ninetyone percent of the patients (43/47) were motor complete.

Thirty-six of the 47 were known to have required endotracheal intubation for an average length of 11.2 days. Twenty-nine individuals required temporary tracheostomy, for an average length of 174.3 days. Fifteen individuals were permanently intubated.

Associated injuries are shown in Table III. Twenty individuals were reported to have head and/or chest injuries. Eight patients had soft tissue neck injuries, and four of these included demonstrable laryngeal fractures.

Table III Associated Injuries

\begin{tabular}{lcc}
\hline & No. & ${ }^{\circ}{ }_{0}$ \\
\hline Head injury & 18 & $\left(38^{\circ}{ }_{o}\right)$ \\
Chest injury & 10 & $\left(21^{\circ}{ }_{o}\right)$ \\
Soft tissue neck injury & 8 & $\left(17^{\circ}{ }_{0}\right)$ \\
Larynx fracture & 4 & $\left(9^{\circ}{ }_{0}\right)$ \\
\hline
\end{tabular}

Table IV Pulmonary Complications

\begin{tabular}{lcc}
\hline & No. ${ }^{\star}$ & ${ }^{\circ}{ }_{\mathrm{o}}$ \\
\hline Pneumonia & 31 & $\left(71^{\circ}{ }_{\mathrm{o}}\right)$ \\
Atelectasis & 30 & $\left(68^{\circ}{ }_{\mathrm{o}}\right)$ \\
Tracheobronchitis & 6 & $\left(14^{\circ}{ }_{\mathrm{o}}\right)$ \\
\hline
\end{tabular}

* Totals more than 47 as some patients had more than one complication.

Table V Symptomatology

\begin{tabular}{lc}
\hline & $\begin{array}{c}\text { Number times } \\
\text { reported }\end{array}$ \\
\hline Dysphonia & 27 \\
Aspiration & 12 \\
Dysphagia & 11 \\
Pain, odynophagia & 10 \\
Dyspnea & 10 \\
Excessive secretions & 10 \\
Stridor & 8 \\
Tracheocutaneous fistula & 7 \\
Difficulty inserting/removing trach tube & 6 \\
Wheezing, bronchitis & 5 \\
Respiratory arrest & 4 \\
Incidental finding on bronchoscopy & 2 \\
Unable to insert suction tube & 1 \\
\hline
\end{tabular}

A wide variety of pulmonary complications were identified in this patient population (Table IV). Pneumonia and atelectasis were detected in more than two-thirds of the patients. Tracheitis and bronchitis were reported less frequently. Other medical complications observed were anaemia, infectious diseases, hypoalbuminemia, hypotension, and dehydration.

The frequency of the symptoms of stenosis is indicated in Table V. Vocalisa- 
tion problems including dysphonia, aphonia, whispered voice or 'air-escape' hoarseness were the most frequently reported symptoms. Aspiration, dysphagia, pain or odynophagia, dyspnea, and a variety of other symptoms were reported less frequently. Although excessive secretions were noted to be the presenting symptom in 10 individuals $(21 \%)$, a review of the records indicated $60 \%$ of the patients had moderate to copious secretions that required frequent suctioning.

The degree of glottic or tracheal stenosis was determined by endoscopy and the patients were classified into four categories of severity. The patients were also divided into categories based upon the location of the stenosis (Table VI): Ten had a glottic stenosis, 19 had a tracheal stenosis, and 18 had both. Eighteen of the individuals with tracheal stenosis had stricture at the stoma area, 12 had a combination of a cuff and a stoma stenosis, five had stenosis in multiple areas, one had only a cuff stenosis, and one had only a tip stenosis.

Table VI Location and Severity of Stenosis

\begin{tabular}{lccccc}
\hline & I & \multicolumn{2}{c}{ Severity classification } & IV & \\
& (mild) & (moderate) & (severe) & $\begin{array}{c}\text { (vory severe } \\
\text { to complete) }\end{array}$ & Total \\
\hline Glottic & 13 & 5 & 7 & 3 & 28 \\
Tracheal & 10 & 12 & 7 & 8 & 37 \\
\hline
\end{tabular}

\section{Radiographic findings}

Radiographic correlation with the endoscopic examination indicated the CT scan was superior to tomography in grading the severity of stenosis (Table VII).

Table VII Radiographic and Endoscopic Correlation of Stenosis Grading

\begin{tabular}{|c|c|c|c|}
\hline & Agree & Disagree & 1 Grade variation \\
\hline \multicolumn{4}{|l|}{ Tomogram } \\
\hline Glottic & $33^{\circ} \mathrm{o}$ & $17^{\circ}{ }_{0}$ & $50 \%$ \\
\hline Tracheal & $67^{\circ}$ & $8^{\circ}{ }_{0}$ & $25^{\circ} \mathrm{o}$ \\
\hline \multicolumn{4}{|l|}{$\mathrm{CT}$} \\
\hline Glottic & $69^{\circ}{ }_{0}$ & $6^{\circ}{ }_{0}$ & $25^{\circ}{ }_{0}$ \\
\hline Tracheal & $73^{\circ}{ }_{0}^{\circ}$ & $9^{\circ}{ }_{0}^{\circ}$ & $18^{\circ}$, \\
\hline
\end{tabular}

Table VIII Endoscopic Findings in Patients with Glottic Stenosis $(\mathbf{N}=28)$

\begin{tabular}{lrc} 
& No. & \\
\hline Inflammatory edema and erythema & 28 & $(100 \%)$ \\
True vocal cord pathology & 19 & $(68 \%)$ \\
Blunting of anterior commissure & 8 & $(29 \%)$ \\
Posterior commissure granulation & 8 & $(29 \%)$ \\
False vocal cord pathology & 8 & $(29 \%)$ \\
Glottic web & 6 & $(21 \%)$ \\
Epiglottic fold thickening & 5 & $(18 \%)$ \\
Cartilage fracture-dislocation & 4 & $(14 \%)$ \\
Arytenoid swelling & 3 & $(11 \%)$ \\
\hline
\end{tabular}

$\star$ Totals more than 28 as some patients had more than one finding. 
CT scan grading had higher agreement with endoscopic grading than did tomographic grading. Roentgenographic examples are shown in Figures 1 to 10.


Figures 1 and 2 Supraglottic Stenosis. The CT scan shows progression from mild thickening of the aryepiglottic folds (arrowhead Fig. 1) to severe stenosis (Fig. 2).

\section{Endoscopic findings}

The endoscopic methods used in these patients included indirect laryngoscopy, direct fiberoptic laryngoscopy or bronchoscopy, and intra-operative rigid laryngoscopy or bronchoscopy. The patients with glottic stenosis had chronic inflammatory edema and erythema (Table VIII). True vocal cord adhesions, fixation, ulceration and decreased mobility were frequent. Other common findings included blunting of the anterior commissure, posterior commissure granulation tissue, and false vocal cord pathology. Table IX shows endoscopic findings in patients with tracheal stenosis. All patients had chronic inflammatory edema and erythema. In addition, granulation or scar tissue, tracheomalacia, tracheal ulceration and tracheal web were noted.

Table IX Endoscopic Findings in Patients with Tracheal Stenosis $(\mathbf{N}=37)$

\begin{tabular}{lcc}
\hline & No. ${ }^{\star}$ & ${ }^{\circ}{ }_{0}$ \\
\hline Inflammatory edema and erythema & 37 & $\left(100^{\circ}{ }_{0}{ }_{0}\right)$ \\
Granulation tissue & 8 & $\left(22^{\circ}{ }_{0}\right)$ \\
Tracheomalacia & 8 & $\left(22^{\circ}{ }_{0}\right)$ \\
Firm cicatricial tissue & 3 & $\left(8^{\circ}{ }_{0}\right)$ \\
Tracheal ulceration & 1 & $\left(3^{\circ}{ }_{0}\right)$ \\
Tracheal web & 1 & $\left(3^{\circ}{ }_{0}\right)$ \\
\hline
\end{tabular}

* Totals more than 37 as some patients had more than one finding. 


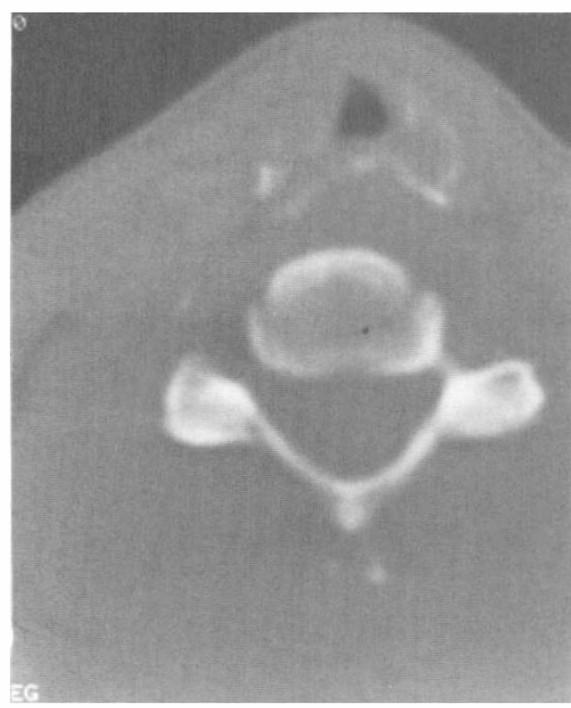

Figure 3

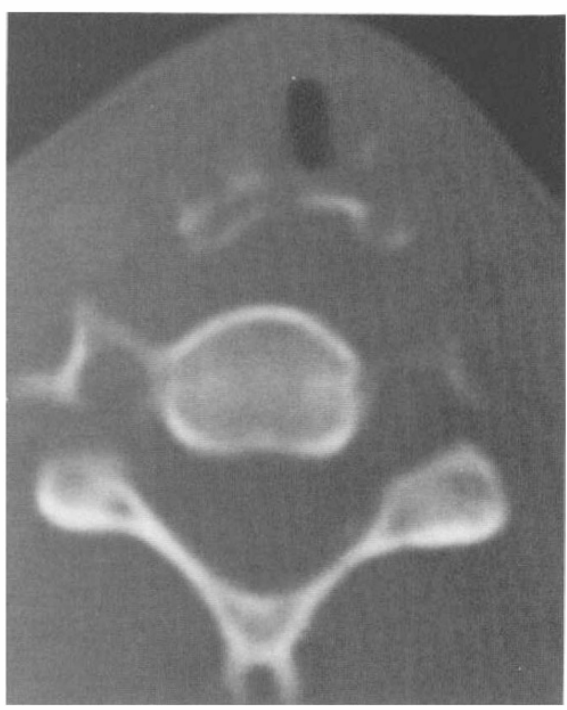

Figure 4

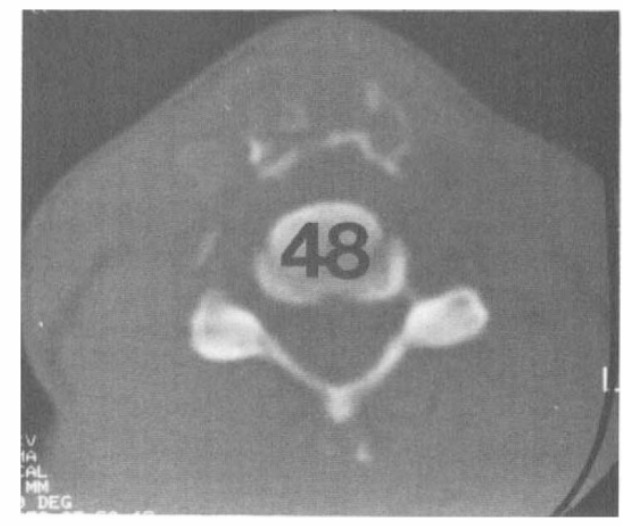

Figure 5

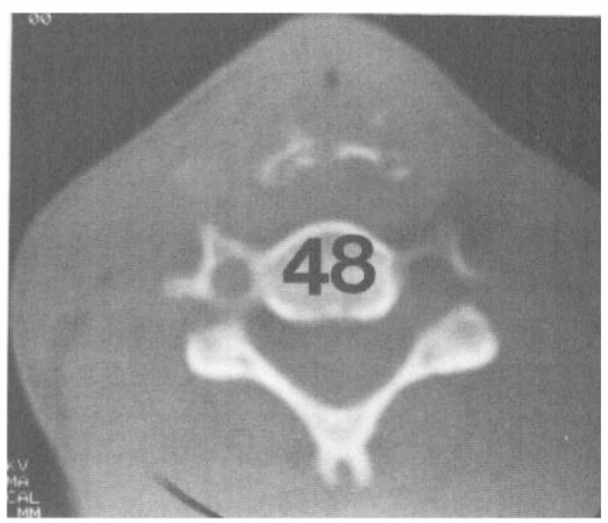

Figure 6

Figures 3 to 6 Glottic Stenosis. The CT scan demonstrates rapid progression over 48 hours from moderate (Fig. 3) to very severe stenosis (Fig. 5) secondary to edema. A different CT cut shows similar progression (Figs 4 and 6 ). 


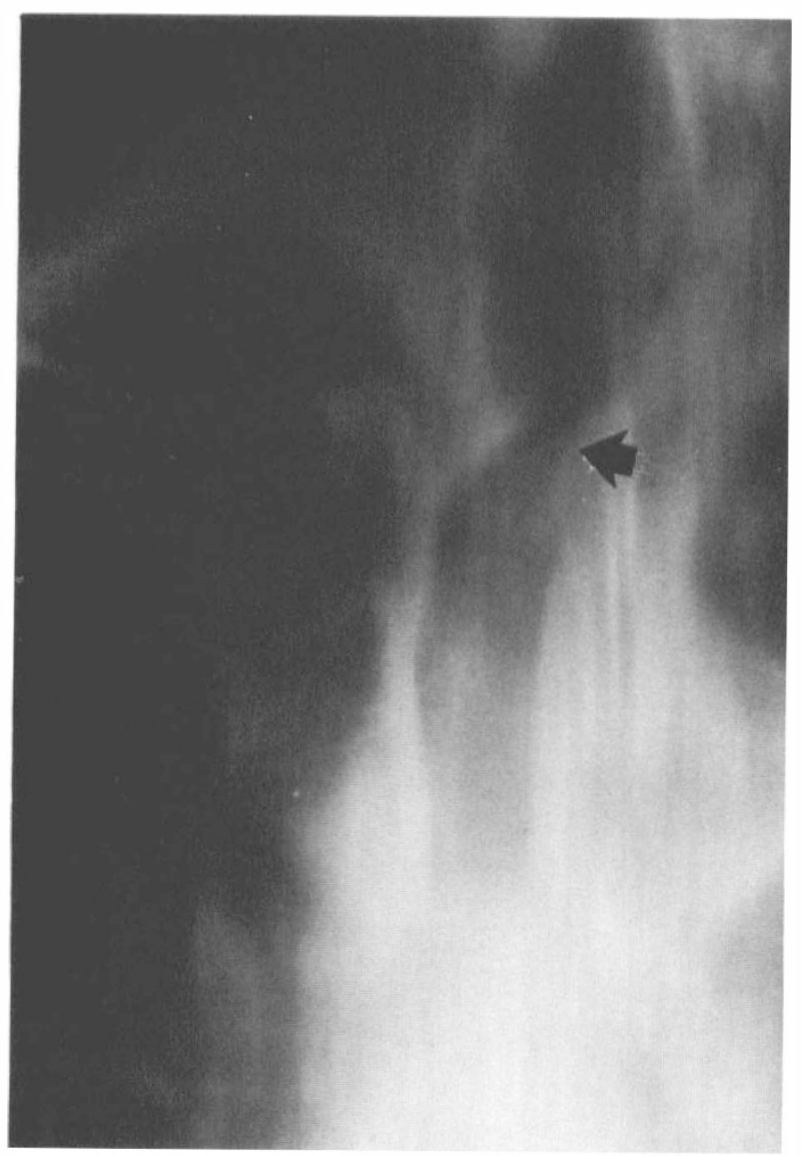

Figure 7 Stomal Stenosis. An AP tomogram shows a $50^{\circ}$ stenosis at the tracheostomy site (arrowhead).

\section{Treatment}

The general medical treatments included improving hydration, correcting any underlying respiratory disease, using antibiotic therapy, correcting anaemia, and providing nutritional support. Oral steroids and local steroid injections were used in four patients, three of whom had grade III or IV stenosis. Three individuals with grade III or IV stenosis received radiation therapy to the granulation tissue. Microendoscopic excision and electrocautery of granulation or scar tissue with dilation of the glottis or trachea was the treatment used for 39 patients. The endoscopic treatment was successful for most of the patients with grade I or II stenosis following one or two dilations. However, patients with grade III or IV stenosis required multiple dilations to maintain an adequate airway (Table X).

Tracheotomy was another method of treatment. A Montgomery tracheal Ttube was inserted in eight patients, six of whom had a grade III or IV stenosis. Four individuals required insertion of a laryngeal keel, of whom three had grade IV stenosis. Six patients required repair of tracheocutaneous fistulae and four 

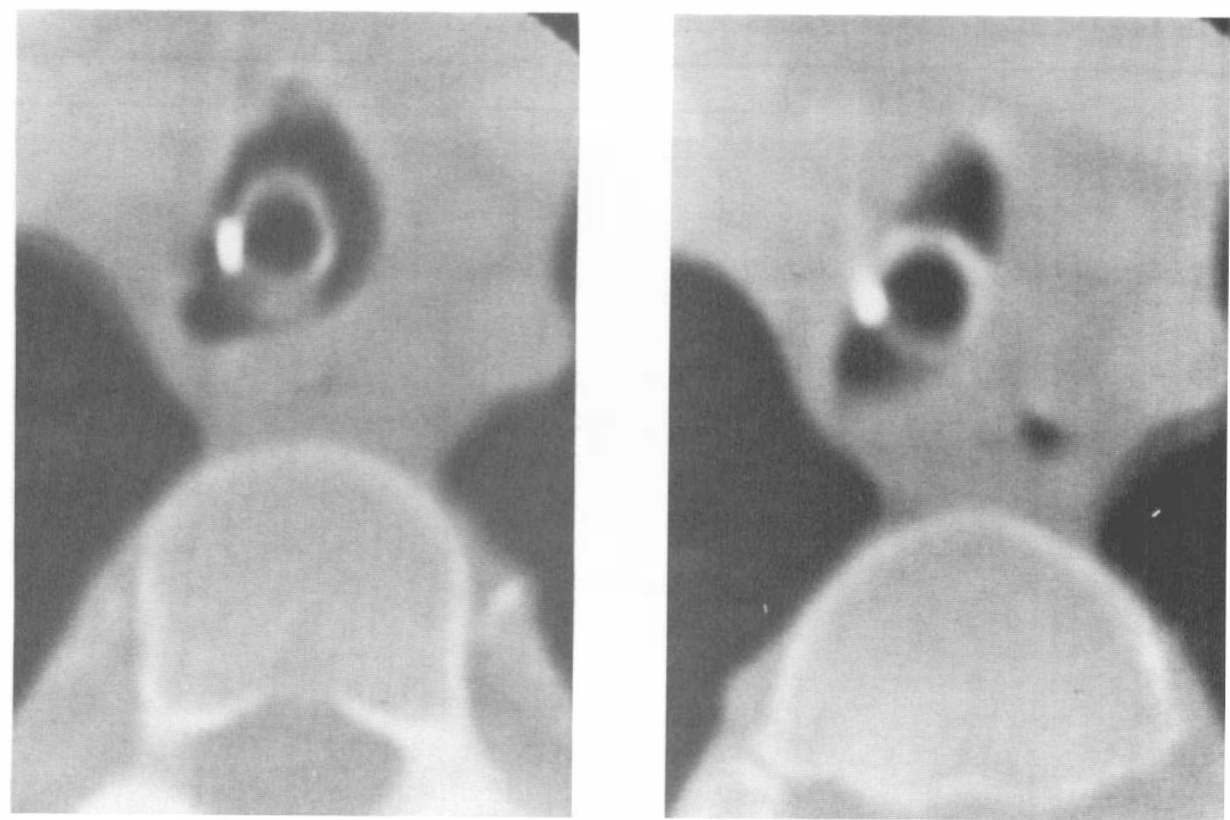

Figures 8 and 9 Cuff and Distal Tube Stenosis. The CT shows the normal calibre of the trachea (Fig. 8) with a small granuloma posterior to the tube. The trachea then narrows $30-40 \%$ (Fig. 9) at the distal cuff site or lower portion of the tracheostomy tube.



Figure 10 Tip Stenosis. A granuloma at the tip of the tracheostomy tube (arrowheads) is severely compromising the outlet. 
Table X Endoscopic Dilation and Severity of Stenosis

\begin{tabular}{cccccc}
\hline & & \multicolumn{5}{c}{ Classification } \\
\cline { 3 - 5 } Dilations & Patients & I & II & II I & IV \\
\hline 1 & 21 & 12 & 7 & 2 & 0 \\
2 & 9 & 3 & 3 & 2 & 1 \\
$3-5$ & 5 & 0 & 0 & 2 & 3 \\
$>5$ & 4 & 0 & 0 & 0 & 4 \\
\hline
\end{tabular}

had a tracheoesophageal fistula repair. There were six individuals who required tracheoplasty, and five of them had grade III or IV stenosis.

Twenty-nine patients were eventually extubated and 15 have permanent tracheotomy tubes at the time of this study. Seven of these individuals require full or part-time ventilator support via the tracheotomy. There are eight patients who are intubated because of unresolved stenosis. Four of the individuals are using Montgomery tracheal $\mathrm{T}$-tubes and the other four utilise various other types of tracheotomy tubes.

Four patients from the study have expired and all of them had tracheotomy tubes at the time of death. One individual was a ventilator dependent quadriplegic with a grade II tip stenosis who died suddenly at home. Another ventilator dependent quadriplegic died during his initial hospitalisation. The pressure on the ventilator was found to be extremely high before death. The autopsy revealed severe inflammation and tracheal stricture from granulation and scar tissue that extended $4 \mathrm{~cm}$ in length. These patients' deaths raise the question of a possible obstruction at the tip of the tube.

\section{Discussion}

Whited (1984), in a prospective study, has shown a $12 \%$ incidence of chronic laryngotracheal stenosis in patients who had endotracheal intubation for more than ten days. Pearson, et al., (1968) and Andrews, et al., (1971) reported approximately $20 \%$ of patients who were managed with tracheotomy and assisted ventilation developed functionally significant tracheal stenosis. Followup studies of survival in critically ill adult patients revealed a $65 \%$ prevalence of tracheal stenosis after tracheotomy (Stauffer, et al., 1981). In our experience, approximately $15 \%$ of all paraplegics and quadriplegics required tracheotomy; $13 \%$ of these had laryngotracheal stenosis.

The majority of persons who incur SCI are injured in motor vehicle accidents. This group of people have an increased chance of laryngeal or tracheal injury. When the SCI patient has a laryngeal or tracheal injury, it is not repaired immediately because of neck instability and other more pressing medical concerns. However, cartilage fracture-dislocations should be reduced as soon as possible. The concern with spinal instability and the avoidance of flexion or extension of the neck creates problems when these patients are intubated (Applebaum, 1979). To minimise glottic and tracheal trauma, there are several steps clinicians can take: (1) Avoid prolonged endotracheal intubation (Whited, 1984). (2) Perform tracheotomy in the operating room and use standard tracheotomy technique to minimise trauma and preserve the integrity of the 
cartilage. (3) Control infection with appropriate antibiotics when indicated (Sasaki, et al., 1979). (4) Avoid high tracheotomy at or above the second tracheal ring (Friedman, et al., 1983). (5) Perform coniotomy only as an emergency measure and convert to a standard tracheotomy as soon as possible. (6) Emphasise local tracheotomy site hygiene by the nursing staff and respiratory therapists (Sasaki, et al., 1979).

Many SCI patients have concomitant head injuries. Due to their agitation and confusion, it is often difficult to secure the tracheotomy and connecting tubing. These patients may require mild sedation and/or restraint to prevent pulling on the tubing. The tracheotomy tube should be tied securely around the neck. Cuff inflation is indicated for several medical conditions, such as aspiration problems, pneumonia, atelectasis, and bronchitis. The length of time a cuff is inflated is related to the degree of pressure necrosis; however, this may be less critical than the pressure of the inflatable cuff (Arola and Anttinen, 1979). This is a problem in the SCI patient because many high level cervical injury patients require tracheotomy and ventilator support. These patients are now surviving longer and are consequently more likely to develop stenosis. A compliant, low pressure cuffed tube should be used (Grillo, et al., 1971). Periodic cuff deflation is necessary to minimise pressure necrosis. Smaller sized tracheotomy tubes are preferred when pulmonary stability has been achieved and should be uncuffed whenever possible. A light, pliable connector between the tracheotomy tube and respirator should be used to reduce stoma problems (Andrews and Pearson, 1971).

Despite improvements in tracheotomy tube contour, the chemical properties of tube materials and introduction of the low pressure cuff, the incidence of glottic or tracheal stenosis is not decreasing. It has been suggested that other medical problems such as anaemia, hypoalbuminemia, and hypotension (Andrews and Pearson, 1971) may contribute to the development of stenosis.

When clinical symptoms suggest glottic or tracheal stenosis, endoscopy is the most reliable diagnostic procedure. Care must be taken to evaluate the entire laryngotracheal complex for the presence of both glottic and tracheal stenosis, even when only one location is suspect. The most commonly used diagnostic radiographic techniques for identifying stenosis are polytomography and CT scanning. Other diagnostic tools include xeroradiography, flow-volume loop (Payne, et al., 1973), acoustic reflection technique (Hoffstein and Zamel, 1984) and contrast laryngotracheogram. Conventional tomography has the advantage of defining the length of a stenotic segment (Gamsu and Webb, 1982). In addition, tomography can be done in patients who have metal tracheotomy tubes, whereas CT imaging is distorted by metal induced artifacts. However, CT is superior in many respects. It can demonstrate adjacent soft tissue structures within and outside the laryngotracheal complex. It is also more accurate in grading stenosis because comparisons of the anterior-posterior diameter, sideto-side diameter, and measurements of the cross-sectional areas can be made (Griscom, et al., 1982). It is possible to reformat CT images in the saggital and coronal planes. CT exposes the patient to less radiation than does tomography. Both CT and tomography are best performed with the tracheotomy tubes removed because it is difficult to define the degree of stenosis with either method when a tube is present (Gamsu and Webb, 1982). The medical and 
safety implications for tube removal must be determined before proceeding with a radiographic evaluation.

There are several treatment options available for glottic and tracheal stenosis. The choices depend upon the severity of the problem (Norris, 1978; Cracovaner and Chodosh, 1978; Bone, 1979; Lucente and Biller, 1979; Montgomery, 1979). The individual with a mild, asymptomatic stenosis can be observed (Geffin, et al., 1971). However, when these individuals develop upper respiratory infections, bronchitis, pneumonia or excessive secretions, the severity of stenosis must be considered while treating the patient. In more severe stenoses, the types of treatment depend on the grade and extent of the stenosis (Simpson, et al., 1982). In the symptomatic patients, the integrity of the cartilage, other respiratory problems, and the tendency towards keloid formation will have an impact on the success or failure of treatment.

The most conservative, safe and least traumatic treatment for stenosis is dilation during endoscopy (Strong, et al., 1979). Gentle dilations augment the natural healing processes (Holinger, et al., 1976) but the success has been inconsistent, particularly in more severe degrees of stenosis.

The $\mathrm{CO}_{2}$ laser is a new method for managing stenosis (Friedman, et al., 1983). It can vaporise scar and granulation tissue with minimal bleeding and with minimal damage to healthy tissue. It can be used during endoscopy or in conjunction with tracheoplasty (Dedo and Sooy, 1984). The successful use of laser treatments depends on the availability of the equipment, the location of the stenosis, the familiarity with its use by the otolaryngologist and anaesthesiologist, and a variety of safety factors.

In this study the actual benefit achieved by four patients receiving oral steroids or intralesional steroid injections is not known. The efficacy of steroids in treating stenosis remains controversial (Bone, 1970; Friedman, et al., 1983). Prolonged steroid usage may predispose the patient to infection and may delay healing. In addition, steroids administered during periods of assisted ventilation may predispose the patient to stoma stenosis (Andrews and Pearson, 1971). Radiation therapy is another treatment option. Limited and localised radiation might be helpful in severe cases of tracheal stenosis, however, over-exposure to radiation may cause scar formation.

If the SCI patient requires general anaesthesia, several precautions should be taken when there is either suspected or known glottic or tracheal stenosis. These patients are difficult to intubate and the anaesthesiologist may be unable to remove the endotracheal tube after surgery. The trauma of intubation may obstruct a marginal airway. During the post-extubation period the patient should be watched carefully for signs of respiratory distress resulting from temporary edema. It has been demonstrated that the majority of patients with tracheal stenosis become symptomatic within two months following extubation (Geffn, et al., 1971; Webber and Grillo, 1978). Dane (1975) has suggested routine endoscopic or radiographic assessment 2 to 4 weeks after extubation.

\section{Conclusion}

Clinicians should be aware of the causes, symptoms and complications related to glottic and tracheal stenosis. This can be a life-threatening situation in the 
SCI patient who already has compromised pulmonary function. A knowledge of the diagnostic and treatment modalities can assist in the early detection and management of this condition.

\section{Acknowledgements}

Appreciation is extended to the Craig Hospital Research and Follow-up Department, Medical Record Department and Education Department and to the Swedish Medical Center Radiology Department for their assistance.

\section{References}

ANDREws MJ, PEARSON FG 1971 Incidence and pathogenesis of tracheal injury following cuffed tube tracheostomy with assisted ventilation: Analysis of a two year prospective study. Annals of Surgery 173:249-263.

APPLEBAUM EL 1979 Laryngeal and tracheal problems in patients with central nervous system and spinal disorders. Otolaryngologic Clinics of North America 12:829-835.

Arola MK, ANtTinen J 1979 Post-mortem findings of tracheal injury after cuffed intubation and tracheostomy. Acta Anaesthesiologica Scandinavica 23:57-68.

Baker JHE, Nuseibeh I, Chung MT, Reddy GV 1984 Layngeal dysfunction in spinal cord injury. Presented at the 1984 Scientific Meeting, International Medical Society of Paraplegia.

BONE RC 1979 Subglottic stenosis. Otolaryngologic Clinics of North America 12:869-875.

Clausen RJ 1932 Unusual sequela of tracheal intubation. Proceedings of the Royal Society of Medicine 25:1507.

Cracovaner AJ, Chodosh PL 1978 vol. 4 Ch. 16. Laryngotracheal Trauma. In: English GM (ed) Otolaryngology. Hagerstown, Harper and Row Publishers, pp. 1-24.

DANE TEB, KING EG 1975 A prospective study of complication after tracheostomy for assisted ventilation. Chest 67:398-404.

DEDO HH, SOOY CD 1984 Endoscopic laser repair of posterior glottic, subglottic and tracheal stenosis by division or micro-trapdoor flap. Laryngoscope 94:445-450.

Friedman EM, Healy GB, MCGill TJI 1983 Carbon dioxide laser management of subglottic and tracheal stenosis. Otolaryngologic Clinics of North America 16:871-877.

Gamsu G, WebB WR 1982 Computer tomography of the trachea. American fournal of Roentgenology 139:321-326.

GeFFIN B, Grillo HC, Cooper JD 1971 Stenosis following tracheostomy for respiratory care. fournal of the American Medical Association 216:1984-1988.

GRILlO HC 1979 Surgical treatment of postintubation tracheal injuries. Fournal of Thoracic and Cardiovascular Surgery 78:860-875.

Grillo HC, Cooper JD, Geffin B, Pontoppidan H 1971 A low pressure cuff for tracheostomy tubes to minimize tracheal injury: A comparative clinical trial. Fournal of Thoracic and Cardiovascular Surgery 62:898-907.

GRISCOM NT 1982 Computed tomographic determination of tracheal dimensions in children and adolescents. Radiology 145:361-364.

HofFSTEIN V, ZAMEL N 1984 Tracheal stenosis measured by the acoustic reflection technique. American Review of Respiratory Disease 130:472-475.

Holinger PH, KuTNick SL, SCHILD JA, Holinger LD 1976 Subglottic stenosis in infants and children. Annals of Otology, Rhinology and Laryngology 85:591-599.

LUCENTE FE, BILLER HF 1979 Subglottic stenosis: Prevention and management. Otolaryngologic Clinics of North America 12:837-840.

MONTGOMERY WW 1979 Management of glottic stenosis. Otolaryngologic Clinics of North America 12:841-847.

NorRis CM 1978 vol. 4, Ch. 30. Bronchology. In: ENGLISH GM (ed) Otolaryngology. Hagerstown, Harper and Row Publishers, pp. 30-32.

Payne WS, Leonard PF, Miller RD, Rosenow III EC, DeSanto LW 1973 Physiologically based assessment and management of tracheal strictures. Surgical Clinics of North America 53:875-884.

PEARSON FG, GoldBerg M, DA Ssilva AJ 1968 Tracheal stenosis complicating tracheostomy with cuffed tubes: Clinical experience and observations from a prospective study. Archives of Surgery 97:380.

SASAKI CT, Horiuchi M, Koss N 1979 Tracheostomy-related subglottic stenosis: Bacteriologic pathogenesis. Laryngoscope 89: 857-865. 
Simpson GT, Strong MS, Shapshay SM, Healy GB, Vaughan CW 1982 Predictive factors of success or failure in the endoscopic management of laryngeal and tracheal stenosis. Annals of Otology, Rhinology and Laryngology 91:384-388.

Stauffer JL, Olson DE, Petty TL 1981 Complications and consequences of endotracheal intubation and tracheotomy: A prospective study of 150 critically ill adult patients. American Fournal of Medicine 70:65-76.

Strong MS, Healy GB, Vaughan CW, Fried MP, Shapshay SM 1979 Endoscopic management of laryngeal stenosis. Otolaryngologic Clinics of North America 12:797-805.

WeBer AL, GrILlo HC 1978 Tracheal Stenosis: An analysis of 151 cases. Radiologic Clinics of North America 16:291-308.

WHITED RE 1984 A prospective study of laryngotracheal sequelae in long-term intubation. Laryngoscope 94:367-377. 